\title{
One-pot co-crystallization of beta and pentasil nanozeolites for the direct conversion of a heavy reformate fraction into xylenes
}

\author{
Vicente J. Margarit ${ }^{\mathrm{a}, 1}$, M. Teresa Portilla ${ }^{\mathrm{a}, 1}$, M. Teresa Navarro ${ }^{\mathrm{a}}$, Raed Abudawoud ${ }^{\mathrm{b}}$, \\ Ibrahim M. Al-Zahrani ${ }^{\mathrm{b}}$, Sohel Shaikh ${ }^{\mathrm{b}}$, Cristina Martínez ${ }^{\mathrm{a}, *}$, Avelino Corma ${ }^{\mathrm{a}, *}$ \\ ${ }^{a}$ Instituto de Tecnología Química, Universitat Politècnica de València-Consejo Superior de Investigaciones Científicas, Avenida de los Naranjos s/n, 46022, Valencia, Spain \\ ${ }^{\mathrm{b}}$ Research \& Development Center, Saudi Aramco, Dhahran, 31311, Saudi Arabia
}

A R T I C L E I N F O

\section{Keywords:}

Nanozeolite

Beta-ZSM-5 co-crystallization

BEA:MFI* aggregates

Dealkylation

Transalkylation

Xylenes

Heavy reformate

\begin{abstract}
A B S T R A C T
Upgrading of the heavy reformate fraction (HR), containing mainly $\mathrm{C}_{9+}$ aromatics, is usually performed by dealkylation or by transalkylation with added benzene and/or toluene to obtain the more valuable xylenes. However, when the costs related to the use of benzene and toluene are considered, the one-step dealkylation/ transalkylation of the $\mathrm{C}_{9+}$ alkylaromatics to xylenes becomes economically attractive. Thus, in a first step, ethylmethylbenzenes (EMB) will have to be dealkylated to toluene, which will then react with the trimethylbenzenes (TMB) present in the HR feed to produce xylenes by transalkylation. Medium pore zeolites will favor dealkylation, whereas large pore zeolites will be more adequate for carrying out the transalkylation reaction. In this work, we present the one-pot synthesis of beta-pentasil aggregates with tunable ratios of the large pore beta to the medium pore component. We show that the close proximity of the beta and pentasil nanocrystals obtained by one-pot co-crystallization synthesis, results in a highly efficient catalyst for the consecutive dealkylation/transalkylation process. The bifunctional catalyst based on the co-crystallized aggregate is more active and selective to xylenes than a catalyst based on a physical mixture of equivalent beta and pentasil nanozeolites synthesized following an analogous procedure. The small crystallite sizes of the co-crystallized zeolites provide the additional advantage of a lower deactivation rate as compared to a reference benchmark catalyst. Results are shown on both, model molecules and industrial HR feed.
\end{abstract}

\section{Introduction}

The heavy reformate stream, containing mainly $\mathrm{C}_{9+}$ aromatics, is the fraction remaining after extraction of the more valuable BTX (benzene, toluene, xylenes) fraction from the catalytic reformate or the pyrolysis gasoline. Traditionally, this fraction was directly added to the gasoline pool. Nowadays, the restriction of the $\mathrm{C}_{6+}$ aromatics content in gasoline due to increasingly stringent environmental regulations, requires alternative ways of upgrading this heavy low-value stream [1].

The main components of the heavy reformate (HR) are ethylmethylbenzenes (EMB) and trimethylbenzenes (TMB), aromatics that can be converted into the more valuable BTX compounds by means of dealkylation of the $\mathrm{C}_{9_{+}}$alkylaromatics [2-6], by transalkylation of these compounds with benzene or toluene [7-12] or by direct conversion of the pure heavy reformate through consecutive/simultaneous dealkylation/transalkylation reactions [1,13-15]. These upgrading reactions are performed industrially in the presence of zeolite based bifunctional catalysts [16]. The zeolites are used in their acid form, and present crystalline structures with pore dimensions close to the sizes of the molecules present in the HR. The topology of the zeolite plays a crucial role in the overall dealkylation/transalkylation reaction scheme [12] and, recently, new synthesis methods have been described for producing zeolite structures with adequate pore dimensions and topologies for selectively catalyzing specific reactions [17]. Additionally, the catalyst contains a hydrogenation function, which has to be able to selectively hydrogenate the olefins formed by dealkylation in order to prevent their undesired oligomerization or possible realkylation of the primary products. Moreover, it will also have to hydrogenate the polyaromatics (naphthalenes) formed, but not the BTX fraction. In both cases, the catalyst life is increased by reducing the formation of coke precursors. Finally, the metal function should not favor hydrogenolysis of alkyl methyl groups. Different metals, such as Pt, Pd, Ni, Re or Mo have been described (see [7] and references therein). Among them, Re, Mo and Pt based catalyst were highly active for dealkylation,

\footnotetext{
* Corresponding authors.

E-mail addresses: cmsanche@itq.upv.es (C. Martínez), acorma@itq.upv.es (A. Corma).

${ }^{1}$ These authors contributed equally.
} 
but the latter, too active, also catalyzed the undesired demethylation. $\mathrm{Ni}$ was less active, and Mo and Re were the two metals with better performance.

Medium pore zeolites can be used for dealkylation of the $\mathrm{C}_{9+}$ alkylaromatic compounds present in the heavy reformate fraction, as dealkylation is favored over transalkylation reactions when using such shape selective zeolite structures [12,7]. Moreover, a possible advantage of this process as compared to disproportionation or transalkylation of the heavy reformate compounds is that the formation of heavier $\mathrm{C}_{10}$ aromatic compounds is avoided, and only light aliphatics and BTX are produced. Still, the diffusional restrictions of the reactants present in a conventional heavy reformate feedstock in these type of zeolites may be a disadvantage regarding overall conversion degrees and productivity. Thus, increasing their accessibility by generation of mesoporosity $[2,18]$ will increase the dealkylation conversion. Large pore zeolites, such as beta [6] or mordenite [19], will also lead to higher conversions, due to lower diffusional restriction through the $12 \mathrm{R}$ channels.

Unlike dealkylation, where ethyl- and propyl-aromatics can be fully converted to BTX and light olefins [7], transalkylation of heavy reformate alkylaromatics with benzene or toluene is thermodynamically controlled, and the maximum xylenes yield obtained will depend on the proportion and type of $\mathrm{C}_{9+}$ aromatics in the feed. Commercial transalkylation processes such as Tatoray ${ }^{s m}$ (UOP) [20,21], TransPlus ${ }^{\text {sm }}$ (ExxonMobil) [22] and TAC-9 (TORAY) [23] use catalysts based on large pore mordenite, but other medium or large pore structures, or a combination of both zeolites have also been described in the open and in the patent literature [24,25]. In fact, the efficiency of the transalkylation process is clearly improved when combining large pore zeolites with 10-ring zeolites [7]. The presence of the latter, more active for deethylation and depropylation, will lead to increased amounts of benzene and toluene available for transalkylation, reducing in this way the amount of $\mathrm{EB}$ and heavy $\mathrm{C}_{10}$ + aromatics, and increasing xylenes selectivity and catalyst life.

A third option is the one-step dealkylation/transalkylation of a $100 \%$ heavy reformate feed, which can be economically attractive due to the higher value of benzene and toluene as compared to that of the heavy aromatic fraction [1]. A recent study over a series of H-Mordenite based catalysts in a fluidized bed reactor at $400^{\circ} \mathrm{C}$ [26] showed that EMB was more reactive than TMB in the conversion of a heavy reformate. Thus, the combination of a first step of EMB dealkylation to toluene, followed by the reaction of this toluene with the TMB, also present in the feed, to produce xylenes by transalkylation, is feasible. Researchers from TORAY Industries described the first process for direct production of xylenes starting from a pure $\mathrm{C}_{9+}$ heavy reformate fraction [13], based on a metal containing mordenite catalyst. Catalysts based on physical mixtures of large and medium pore zeolites have also been described for the transalkylation of a heavy reformate in the absence of added toluene (or benzene) [27]. The benefits offered by these multizeolitic based transalkylation catalysts, containing a medium pore zeolite as the active dealkylation component, are substantial because benzene and/or toluene will have to be produced in-situ from the $\mathrm{C}_{9+}$ aromatics (mainly EMB) contained in the feed, and a highly efficient dealkylation function will be mandatory. Moreover, both, the dealkylation and the transalkylation components will have to be optimized and balanced in order to obtain the highest overall xylenes production.

In the case of multizeolitic catalysts, such as those described above, an interesting approach would be to co-crystallize, by means of a onepot methodology, aggregates with the targeted proportion of the desired zeolite structures.

Here we present a dealkylation/transalkylation catalyst based on beta/pentasil aggregates obtained by means of a one-pot co-crystallization of the two structures in the presence of $\mathrm{N}_{4}$-phe- $\mathrm{C}_{6}(\mathrm{OH})_{4}$ as the single organic structure directing agent. A careful analysis of the PXRD pattern reveals that the pentasil component is a MFI-MEL intergrowth, with a proportion of the MFI phase above $85 \%$ (MFI*). The synthesis procedure enables the synthesis of BEA and MFI* as single phases and of BEA/MFI* aggregates with different proportions of the two zeolites, by adjusting the composition of the synthesis gel. When the two zeolites are crystallized simultaneously, they are obtained as individual nanocrystals with different morphology, zeolite BEA as spherical crystallites with average sizes below $50 \mathrm{~nm}$, and zeolite MFI* as nanolayers [28]. BEA and MFI* form aggregates in a way that they enhance the consecutive reaction steps for dealkylation of EMB to toluene on the medium pore zeolite and its transalkylation with the TMB, also present in the feed, on the large pore zeolite. This leads to bifunctional catalysts, which are highly effective in the direct conversion of a heavy reformate stream to the more valuable xylenes.

\section{Experimental}

\subsection{OSDA synthesis}

\subsection{1. $N_{4}-$ phe- $C_{O}$}

In a first step, $0.2 \mathrm{~mol}$ of N,N,N',N'-tetramethyl-1,6-diaminohexane was dissolved in $100 \mathrm{~mL}$ of acetonitrile in a $500 \mathrm{~mL}$ round bottom flask and kept cold in an ice-bath. Using an addition funnel, $0.02 \mathrm{~mol}$ of $\alpha, \alpha$ 'dichloro-p-xylene dissolved previously in $100 \mathrm{~mL}$ of acetonitrile was added dropwise. The mixture was warmed-up to $50^{\circ} \mathrm{C}$ and stirred for $24 \mathrm{~h}$. The solid was precipitated using diethylether, filtered under $\mathrm{N}_{2}$ flow and washed with more diethyl ether. Finally, the product was dried in vacuum.

\subsection{2. $N_{4}-$ phe $-C_{6}$}

$0.06 \mathrm{~mol}$ of 1 -Bromohexane was added to $0.02 \mathrm{~mol}$ of $\mathrm{N}_{4}$-phe- $\mathrm{C}_{0}$ dissolved in $100 \mathrm{~mL}$ of methanol in a $250 \mathrm{~mL}$ round bottom flask. The mixture was warmed-up to $70{ }^{\circ} \mathrm{C}$ and maintained for $24 \mathrm{~h}$. Final product was concentrated under reduced pressure, precipitated with diethylether, filtered and washed with more diethyl ether. The white solid obtained was dried in vacuum. In order to obtain the OSDA in its hydroxide form, it was ion exchanged using a basic resin.

\subsection{Zeolite synthesis}

Four different zeolite materials, including single beta (BEA), single pentasil (MFI*) and one-pot synthesized beta-pentasil aggregates with different proportions of the two zeolites, were prepared varying the composition of the synthesis gel. In order to synthesize the zeolite combination with a larger proportion of beta zeolite (60BEA:40MFI*), $22.5 \mathrm{~g}$ of the silicon source (Ludox AS-40, Sigma-Aldrich) was added to $71.58 \mathrm{~g}$ of a solution of $\mathrm{N}_{4}$-phe- $\mathrm{C}_{6}(\mathrm{OH})_{4}\left(10.8 \mathrm{wt} \%\right.$ of $\mathrm{N}_{4}-\mathrm{phe}^{-\mathrm{C}_{6}}(\mathrm{OH})_{4}$ in $\mathrm{H}_{2} \mathrm{O}$, see Fig. 1) and stirred vigorously.

To this mixture, $0.51 \mathrm{~g}$ of the aluminum source (CATAPAL A, $\mathrm{Al}_{2} \mathrm{O}_{3}$ $74.6 \%$, SASOL) was added and the resulting gel was stirred continuously until reaching the desired amount of water in the gel, e.g., when the mass of the gel matched the expected mass according to the compositions corresponding to the desired beta:pentasil ratio enclosed in Table 1. The gel with the desired composition was introduced into $35 \mathrm{~mL}$ Teflon-lined autoclaves and kept for $7 \mathrm{~d}$ at $150^{\circ} \mathrm{C}$ under stirring at $60 \mathrm{rpm}$ and autogenous pressure. The synthesis gels for the other BEA/MFI* mixtures and for the single BEA and MFI* samples are prepared following the same procedure but using the molar compositions provided in Table 1 .

In the following sections, the samples will be named as BEA for the pure beta zeolite, $\mathrm{MFI}^{*}$ for the single pentasil zeolite, and 60BEA:40MFI* and 40BEA:60MFI* for the aggregates with larger and smaller proportion of beta zeolite, respectively.

\subsection{Catalyst preparation}

The zeolites have been impregnated with rhenium $(0.5 \mathrm{wt} \% \mathrm{Re})$ following the incipient wetness procedure and using ammonium 


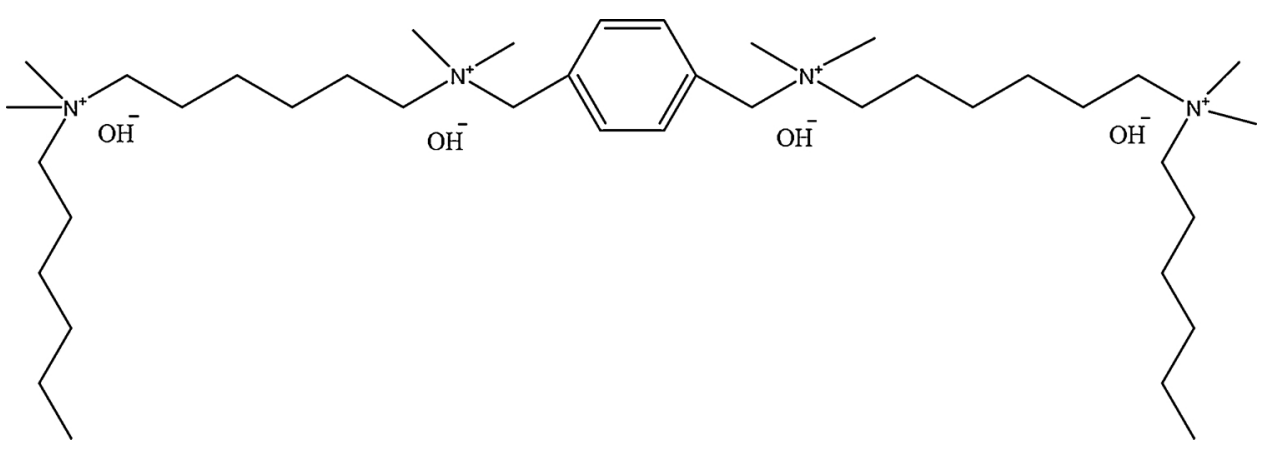

Fig. 1. $\mathrm{N}_{4}-$ phe- $\mathrm{C}_{6}(\mathrm{OH})_{4}$ used for the synthesis of the BEA:MFI* aggregates.

perrhenate $\left(\mathrm{NH}_{4} \mathrm{ReO}_{4}\right)$ as the metal precursor. After the metal loading, the samples are stored in a desiccator for at least $5 \mathrm{~h}$, and then dried at $100{ }^{\circ} \mathrm{C}$ overnight. The samples were calcined in a fixed bed reactor, increasing temperature up to $500{ }^{\circ} \mathrm{C}$ in $100 \mathrm{~mL} \mathrm{~min}^{-1}$ of $\mathrm{N}_{2}$ (at a heating rate of $3{ }^{\circ} \mathrm{C} \mathrm{min}^{-1}$ ), keeping it at $500{ }^{\circ} \mathrm{C}$ for $3 \mathrm{~h}$ under air flow $\left(100 \mathrm{~mL} \mathrm{~min}^{-1}\right)$, and then cooling down to room temperature or to the activation temperature under $\mathrm{N}_{2}$ flow $\left(100 \mathrm{~mL} \mathrm{~min}^{-1}\right)$. The catalyst based on the BEA/MFI* physical mixture was prepared by blending of the $0.5 \mathrm{wt} \%$ Re containing single zeolites, synthesized as described in Section 2.2.

A bifunctional composite catalyst supplied by Saudi Aramco, SA25, based on a beta/ZSM-5 physical mixture in an alumina binder and containing $1.0 \mathrm{wt} \%$ of a noble metal, was used as benchmark reference.

\subsection{Characterization methods}

The structure of the solids was confirmed by powder X-ray diffraction (PXRD) using a Philips X'Pert diffractometer equipped with a graphite monochromator, operating at $40 \mathrm{kV}$ and $45 \mathrm{~mA}$ and using nickel-filtered $\mathrm{Cu} \mathrm{K} \alpha$ radiation $(\lambda=0.1542 \mathrm{~nm})$. Their chemical composition was determined by means of a 715-ES inductively coupled plasma (ICP) Optical Emission spectrometer after dissolution of the solids in a $\mathrm{HNO}_{3} / \mathrm{HF}$ solution. Textural properties were determined from the $\mathrm{N}_{2}$ adsorption isotherms measured on a Micromeritics ASAP 2020 at $-196{ }^{\circ} \mathrm{C}$. Prior to the adsorption measurements, the samples were degassed at $450^{\circ} \mathrm{C}$ for $24 \mathrm{~h}$.

The relative concentration of acidic sites in the different samples was obtained by FT-IR spectroscopy using pyridine as the probe molecule. Pyridine adsorption/desorption experiments were carried out on self-supported wafers $\left(10 \mathrm{mg} \cdot \mathrm{cm}^{-1}\right)$ activated at $400^{\circ} \mathrm{C}$ and $10^{2} \mathrm{~Pa}$ for $2 \mathrm{~h}$. After sample activation, pyridine vapor $\left(6.5 .10^{2} \mathrm{~Pa}\right)$ was admitted into the IR cell and adsorbed on the zeolite at room temperature. Desorption was performed under vacuum over three consecutive $1 \mathrm{~h}$ periods of heating at 150,250 , and $350^{\circ} \mathrm{C}$, each of them followed by an IR measurement at room temperature. All the spectra were normalized to the area of the corresponding Si-O overtones $\left(1755-2100 \mathrm{~cm}^{-1}\right)$. The amount of Brønsted and Lewis acid sites was determined from the intensities of the bands at ca. 1545 and $1450 \mathrm{~cm}^{-1}$, respectively, using the molar extinction coefficients given by Emeis [29].

Morphology and size of zeolite crystals were studied by transmission electron microscopy (TEM) in a JEOL microscopy model JEM 1010 $(100 \mathrm{kV})$ microscope. Before TEM observation, the samples were prepared by suspending the solid in isopropanol, sonicating for $10 \mathrm{~min}$, and placing one drop on a carbon-coated copper grid (300 mesh). A field emission scanning electron (FESEM) microscope, equipped with a Secondary Electron detector (SED) and a back-scatter detector (BSE) was used to study the topography and the metal dispersion of the final catalysts, respectively.

NMR spectra of the solids were recorded at room temperature under magic angle spinning (MAS) in a Bruker AV-400 spectrometer. The ${ }^{27} \mathrm{Al}$ spectra were acquired at $104.218 \mathrm{MHz}$ with a spinning rate of $10 \mathrm{kHz}$ at a $90^{\circ}$ pulse length of $0.5 \mu$ s with $1 \mathrm{~s}$ repetition time referred to a $0.1 \mathrm{M}$ aqueous solution of $\mathrm{Al}\left(\mathrm{NO}_{3}\right)_{3}$.

\subsection{Catalytic tests}

\subsubsection{Conversion of model mixture}

Catalytic tests with a model feed were performed in a highthroughput reaction system of 16 continuous fixed-bed parallel microreactors with $6 \mathrm{~mm}$ inner diameter (Spider reactor) [12]. Each reactor can be fed independently with the desired flows of hydrocarbon mixture and $\mathrm{H}_{2}$, making it possible to operate in a wide range of contact times and hydrogen/hydrocarbon ratios. The liquid feed was a mixture of para-ethylmethylbenzene $(30 \mathrm{wt} \%)$ and 1,2,4-trimethylbenzene (70 wt\%).

The simultaneous catalytic experiments were carried out at 20 bar total pressure, temperatures of 350,375 and $400{ }^{\circ} \mathrm{C}$, hydrogen/hydrocarbon molar ratio of 8.5 , reaction time of $16 \mathrm{~h}$, and WHSV $=10 \mathrm{~h}^{-1}$. The amount of catalyst (particle size $0.2-0.4 \mathrm{~mm}$ ) in each fixed-bed microreactor was $0.125 \mathrm{~g}$ diluted with $\mathrm{SiC}$ to a total bed volume of $2.0 \mathrm{~mL}$. In the case of the reference SA25 catalysts containing an $\mathrm{Al}_{2} \mathrm{O}_{3}$ matrix, the amount of catalyst charged was adjusted in order to have $0.125 \mathrm{~g}$ of the zeolite. These reaction conditions were confirmed to be free of internal or external mass control.

Reaction products were analyzed by on-line gas chromatography in a Bruker 450 GC provided with two independent channels. The permanent gases (Ar as internal standard and $\mathrm{H}_{2}$ ), methane (when present) and ethane are analyzed in a channel equipped with a TCD and three columns, a Hayesep N pre-column (0.5 m length), a Hayesep Q $(1.5 \mathrm{~m})$ and a $13 \mathrm{X}$ molecular sieve (1.2 m length). In a second channel the $\mathrm{C}_{1}-\mathrm{C}_{4}$ hydrocarbons are first separated from the aromatics in a CP-Wax capillary column (5.0 m length and $0.32 \mathrm{~mm}$ inner diameter). The $\mathrm{C}_{1}-\mathrm{C}_{4}$ gases are then separated in a CP-Porabond Q $(25 \mathrm{~m}$ length and $0.32 \mathrm{~mm}$ inner diameter) and detected in a FID, whereas the aromatics are

Table 1

Gel Compositions.

\begin{tabular}{ll}
\hline Sample & Composition \\
\hline $\mathrm{BEA}(\mathrm{Si} / \mathrm{Al}=20)$ & $1 \mathrm{SiO}_{2}: 0.025 \mathrm{Al}_{2} \mathrm{O}_{3}: 0.125 \mathrm{~N}_{4}-\mathrm{phe}_{\mathrm{C}}(\mathrm{OH})_{4}: 20 \mathrm{H}_{2} \mathrm{O}$ \\
60BEA:40MFI* $(\mathrm{Si} / \mathrm{Al}=20)$ & $1 \mathrm{SiO}_{2}: 0.025 \mathrm{Al}_{2} \mathrm{O}_{3}: 0.075 \mathrm{~N}_{4}-\mathrm{phe}-\mathrm{C}_{6}(\mathrm{OH})_{4}: 20 \mathrm{H}_{2} \mathrm{O}$ \\
40BEA:60MFI$(\mathrm{Si} / \mathrm{Al}=30)$ & $1 \mathrm{SiO}_{2}: 0.017 \mathrm{Al}_{2} \mathrm{O}_{3}: 0.075 \mathrm{~N}_{4}-\mathrm{phe}_{6}(\mathrm{O})_{4}: 20 \mathrm{H}_{2} \mathrm{O}$ \\
$\mathrm{MFI}^{*}(\mathrm{Si} / \mathrm{Al}=50)$ & $1 \mathrm{SiO}_{2}: 0.01 \mathrm{Al}_{2} \mathrm{O}_{3}: 0.1 \mathrm{~N}_{4}-\mathrm{phe}_{6}-\mathrm{C}_{6}(\mathrm{OH})_{4}: 20 \mathrm{H}_{2} \mathrm{O}$ \\
\hline
\end{tabular}


Table 2

Composition of industrial Heavy Reformate.

\begin{tabular}{ll}
\hline Component & wt $\%$ \\
\hline $\mathrm{AC}_{8}$ & 3.80 \\
Ethylbenzene & 0.03 \\
$p$-xylene & 0.15 \\
$m$-xylene & 0.38 \\
$o$-xylene & 3.38 \\
$i$-propylbenzene & 0.43 \\
$n$-propylbenzene & 2.07 \\
Ethyl-methylbenzene (EMB) & 19.42 \\
$m$ - and p-EMB & 15.33 \\
$o$ - EMB & 4.29 \\
Trimethylbenzene (TMB) & 60.63 \\
$1,3,5-T M B$ & 11.69 \\
$1,2,4$-TMB & 40.81 \\
1,2,3-TMB & 8.13 \\
$\mathrm{AC}_{10}+$ & 13.33 \\
\hline
\end{tabular}

further separated in a second CP-Wax $(1.0 \mathrm{~m}$ length and $0.32 \mathrm{~mm}$ inner diameter) connected to a second FID. This configuration allows complete analysis of the reaction mixture in $10 \mathrm{~min}$.

\subsubsection{Conversion of an industrial heavy reformate (HR)}

An industrial heavy reformate (HR) supplied by Saudi Aramco was processed in a fixed-bed stainless-steel tubular reactor having a $10.5 \mathrm{~mm}$ i.d. and $20 \mathrm{~cm}$ length. The reactor was charged with $0.75 \mathrm{~g}$ of catalyst (otherwise indicated) sieved to a particle size of $0.2-0.4 \mathrm{~mm}$ and diluted with $\mathrm{SiC}$ up to a total bed volume of $5.0 \mathrm{~mL}$. In the case of the reference SA25 catalysts containing an $\mathrm{Al}_{2} \mathrm{O}_{3}$ matrix, the amount of catalyst charged was adjusted in order to have $0.75 \mathrm{~g}$ of the zeolite. Gaseous compounds $\left(\mathrm{H}_{2}\right.$ and $\left.\mathrm{N}_{2}\right)$ were fed into the system by mass flow meters via a vaporizer, and nitrogen is employed as internal reference. The liquid industrial feedstock, whose composition is given in Table 2, was fed to the vaporizer by means of a HPLC pump.

Prior to the catalytic test, the catalyst was calcined following the calcination procedure detailed in Section 2.2, and reduced in situ at $450{ }^{\circ} \mathrm{C}$ for $1 \mathrm{~h}$ under $\mathrm{H}_{2}$ flow $\left(50 \mathrm{~mL} \mathrm{~min}^{-1}\right)$, at atmospheric pressure. The reaction was performed at $20 \mathrm{bar}$, during consecutive periods of $5 \mathrm{~h}$ at temperatures of 350,375 and $400{ }^{\circ} \mathrm{C}$, WHSV of $10 \mathrm{~h}^{-1}$ and a $\mathrm{H}_{2} / \mathrm{HC}$ of 4:1 $\mathrm{M}$ ratio. It was checked that under these experimental conditions the reaction was not controlled by internal or external diffusion. During reaction, the effluent stream was analyzed on-line in a Varian CP3800 gas chromatograph with two detection channels. The first one is equipped with a TCD and allows separation, identification and quantification of permanent gases and light hydrocarbons $\left(\mathrm{C}_{1}-\mathrm{C}_{5}\right)$. The heavier hydrocarbons $\left(\mathrm{C}_{6+}\right)$ are separated in a WAX capillary column ( $60 \mathrm{~m}$ length, $0.2 \mathrm{~mm}$ inner diameter) and detected by a FID. Nitrogen was employed as internal reference allowing an accurate quantification of the amount and distribution of the reaction products.

\section{Results and discussion}

As described in the introduction, the appropriate combination of medium and large pore zeolites has important benefits when converting a heavy reformate feed without the addition of benzene or toluene. The medium pore zeolite will favor the deethylation of EMB, whereas the large pore zeolite component will catalyze the transalkylation of TMB present in the feed with the toluene produced in-situ. Due to the consecutive nature of these two reactions, the proximity of the two zeolite structures could be beneficial. Following the procedure detailed in the experimental section, two BEA/MFI* mixtures with different proportion of the two structures have been synthesized starting from synthesis gels with the compositions presented in Table 1. Adjusting the gel composition, we have also synthesized the single BEA and $\mathrm{MFI}^{*}$ zeolites. The characterization of the different samples and their catalytic behavior is

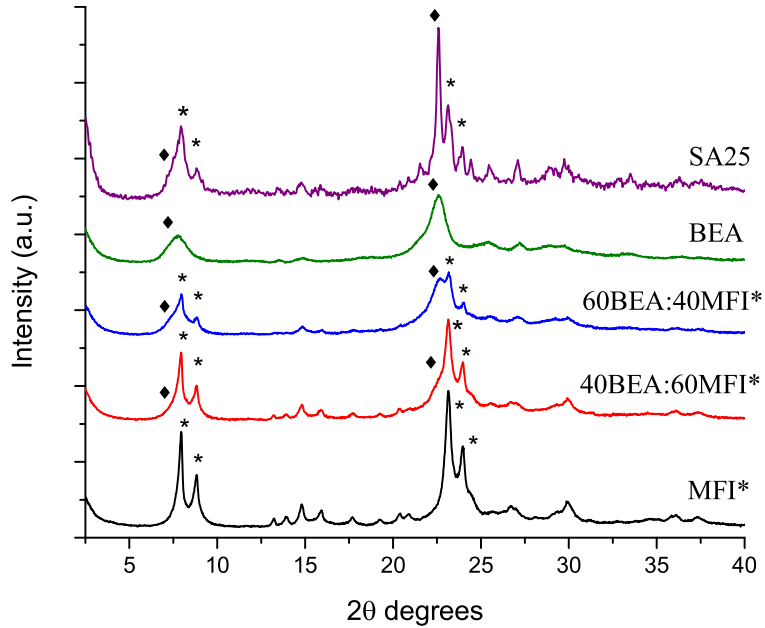

Fig. 2. PXRD patterns of reference catalyst SA25 and of the single BEA, single $\mathrm{MFI}^{*}$ and one-pot synthesized BEA:MFI* aggregates, calcined. Characteristic peaks of the MFI* structure $\left(^{*}\right)$ and of the BEA structure $(\bullet)$ are marked.

described in the following sections.

\subsection{Zeolite synthesis and characterization}

The structures of the large pore beta and the medium pore pentasyl phases have been confirmed by PXRD (see Fig. 2 for the diffractograms of the calcined zeolites). The low intensity and the broadness of the diffraction peaks suggest a small crystal size in both cases, probably in the nanometer range. Regarding the pentasil structure, a careful analysis of the XRD pattern evidences the broadening of the (133) reflection at ca. 24.4( $2 \theta$ degree), a clear indication of the disordered structure of the phase obtained and of the presence of an intergrowth of MFI and MEL-type zeolites [30,31]. The frameworks of these two zeolites, ZSM-5 and ZSM-11, respectively, can be built by considering the same Periodic Building Unit (PerBU) (a 2D bc-layer) [30]. In the case of pure MFI, this PerBUs are connected to each other by inversion (i) symmetry operation, while in pure MEL by mirror (m) symmetry operation. Under particular synthesis conditions, both $i$ and $m$-types of stacking may exist in the same crystal, leading to the formation of disordered (intergrown) structures. Comparing the relative intensities of the XRD pattern obtained for our single pentasil sample with those presented in the literature [30-32] the probability of m-type of stacking and, therefore, the proportion of MEL phase in our medium pore zeolite has been estimated to be around $10-15 \%$. Considering the large similarity of the two phases, MFI and MEL, and taking into account that the presence of small amounts of MEL should not affect the catalytic behavior of the catalysts described here, the pentasil component will be identified as MFI* along the rest of the work.

Comparison of the intensity of the main peaks corresponding to the large pore beta zeolite ( 7.6 and 22.4 ( $2 \theta$ degree)) and for the medium pore zeolite $(7.9,8.8,23.1$ and 23.9 ( $2 \theta$ degree)) allows estimating the proportion of each of them present when co-crystallizing the betapentasil aggregates. In this way, bi-zeolite systems with BEA:MFI* proportions of 60:40 and 40:60 (wt/wt) have been produced and further characterized. The benchmark SA25 catalyst is included for comparison, and PXRD shows the characteristic peaks of the BEA and MFI structure as the only crystalline components.

The physico-chemical and acidic properties of the zeolites obtained are enclosed in Tables 3 and 4, and compared with those of the reference catalyst SA25. The high external surface areas $\left(\geq 167 \mathrm{~m}^{2} \mathrm{~g}^{-1}\right)$ and mesopore volumes $\left(\geq 0.34 \mathrm{~cm}^{3} \mathrm{~g}^{-1}\right)$ of the single beta and pentasil zeolites synthesized suggest small crystallite sizes, in the nanometer range [33] and smaller in the case of the large pore beta. Moreover, the composition and the textural properties of the BEA/MFI* aggregates is 
Table 3

Physico-chemical properties of reference catalyst SA25, single BEA, single MFI* and one-pot synthesized BEA:MFI" aggregates, before and after Re-loading.

\begin{tabular}{|c|c|c|c|c|c|c|c|}
\hline \multirow[b]{2}{*}{ Sample } & \multicolumn{2}{|l|}{ ICP } & \multirow[t]{2}{*}{$\mathrm{S}_{\mathrm{BET}}\left(\mathrm{m}^{2} \mathrm{~g}^{-1}\right)$} & \multirow[t]{2}{*}{$\mathrm{S}_{\text {micro }}\left(\mathrm{m}^{2} \mathrm{~g}^{-1}\right)$} & \multirow[t]{2}{*}{$S_{\text {Ext }}\left(m^{2} g^{-1}\right)$} & \multirow[t]{2}{*}{$\mathrm{V}_{\text {micro }}\left(\mathrm{cm}^{3} \mathrm{~g}^{-1}\right)$} & \multirow[t]{2}{*}{$V_{\text {meso }}\left(\mathrm{cm}^{3} \mathrm{~g}^{-1}\right)$} \\
\hline & $\mathrm{Si} / \mathrm{Al}$ & $\operatorname{Re}(w t \%)$ & & & & & \\
\hline SA25 & 2.9 & $1.0^{*}$ & 457 & 372 & 85 & 0.18 & 0.26 \\
\hline BEA & 17.5 & - & 633 & 337 & 296 & 0.16 & 0.41 \\
\hline $\mathrm{Re} / \mathrm{BEA}$ & 17.5 & 0.47 & 614 & 315 & 298 & 0.15 & 0.42 \\
\hline 60BEA:40MFI" & 17.6 & - & 642 & 349 & 293 & 0.17 & 0.39 \\
\hline $\mathrm{Re} /\left(60 \mathrm{BEA}: 40 \mathrm{MFI}^{\prime \prime}\right)$ & 16.7 & 0.52 & 595 & 316 & 278 & 0.15 & 0.39 \\
\hline 40BEA:60MFI & 25.8 & - & 569 & 356 & 212 & 0.17 & 0.34 \\
\hline $\mathrm{Re} /\left(40 \mathrm{BEA}: 60 \mathrm{MFI}^{\prime \prime}\right)$ & 25.5 & 0.45 & 550 & 343 & 207 & 0.17 & 0.34 \\
\hline MFI & 37.4 & - & 513 & 346 & 167 & 0.17 & 0.34 \\
\hline $\mathrm{Re} / \mathrm{MFI}^{*}$ & 40.5 & 0.53 & 505 & 336 & 170 & 0.16 & 0.37 \\
\hline
\end{tabular}

* $1.0 \mathrm{wt} \%$ noble metal.

intermediate as compared to the single zeolites. Indeed, the mixture containing more BEA presents lower $\mathrm{Si} / \mathrm{Al}$ ratio and higher BET, closer to those of the pure beta zeolite, than the sample with less beta. On the other hand, the mixture containing more $\mathrm{MFI}^{*}$ presents a micropore surface area closer to that of the pure medium pore zeolite (higher $\mathrm{Si}$ / $\mathrm{Al}$, lower BET). Thus, the physico-chemical properties of the mixtures are consistent with the proportion of BEA and MFI* determined by PXRD when compared to the single zeolites.

It is important to note that the external surface areas and mesopore volumes of the four samples synthesized following this new procedure are significantly higher than those obtained for the reference catalyst, which contains an alumina binder (see Table 4). This can be due to the small crystal sizes of the synthesized zeolites, which are confirmed by TEM (see Fig. 3) and FESEM (see Fig. 4). The images also show a different morphology for the single MFI* (layers, see Figs. 3A and 4 A) and BEA (isotropic nanocrystals, see Figs. 3B and 4 B) zeolites, and the different shapes can be clearly identified in the samples containing both BEA and MFI* zeolites, which present a combination of both morphologies (see Figs. 3C-D and 4 C-D). Indeed, the higher proportion of the beta nanocrystals is clearly observed in sample 60BEA:40MFI* as compared to 40BEA:60MFI*. These results are in good agreement with the different proportion of the two zeolitic materials estimated by XRD and by the textural properties.

The acidity of the different samples has been measured by FT-IR combined with pyridine adsorption-desorption (see Table 4). The Brønsted acid site (BAS) density correlates well with the Si/Al molar ratio of the different zeolites. Thus, BEA and 60BEA:40MFI*, both with $\mathrm{Si} / \mathrm{Al}$ around 17 , have similar amounts of BAS at the different pyridine desorption temperatures, sample 40BEA:60MFI* $(\mathrm{Si} / \mathrm{Al}=25.8)$ presents lower amount of BAS than the two former zeolites and the pure
$\mathrm{MFI}^{*}$, containing less $\mathrm{Al}(\mathrm{Si} / \mathrm{Al}=37.4)$ presents the lowest BAS density. The amount of Lewis acid sites (LAS) of the Re-free samples correlates well with the intensity of the band assigned to octahedral $\mathrm{Al}$ determined by ${ }^{27}$ Al-NMR (see Fig. 5-A) BEA $~$ 60BEA:40MFI* $>40$ BEA:60MFI* > MFI*.

In order to be used as catalysts for the conversion of a heavy reformate to xylenes, the acid zeolites described so far have been impregnated with $0.5 \mathrm{wt} \%$ rhenium, which contributes with a mild hydrogenation capacity. In good agreement with the low metal content, the metal dispersion is high, according to the FESEM-BSE images shown in Fig. 4E-H.

The physico-chemical and acidic properties of the $0.5 \mathrm{wt} \% \mathrm{Re}$ loaded samples are compared in Tables 3 and 4 with those of the parent metal-free zeolites. The addition of the rhenium has only a minor influence on the textural properties of the samples, as could be expected from the low metal content. Regarding the acidity of the Re-containing zeolites, the incorporation of the metal leads in all cases to a small (in some cases insignificant) decrease of the amount of BAS and LAS. This small reduction can be due to the presence of some cationic Re species in charge compensating sites or to the slight increase of the extraframework $\mathrm{Al}$ generated during the calcination performed after Re incorporation, or to its redistribution. In fact, the addition of Re affects the octahedrally coordinated aluminum, as can be deduced from the changes in the octahedral region of the ${ }^{27} \mathrm{Al}-\mathrm{NMR}$ spectra of the samples. The differences in intensity of the band at $\sim 0 \mathrm{ppm}$ among the different catalysts is reduced as compared to the Re-free samples, and a broad band appears at lower chemical shifts, which has been assigned to extraframework Al species with distorted octahedral geometry [34] (see Fig. 5 A). It is interesting to note that the BAS density of the Reloaded mixtures obtained by co-crystallization is higher than the

Table 4

Acidic properties of reference catalyst SA25, single BEA, single MFI* and one-pot synthesized BEA:MFI* aggregates, before and after Re loading obtained by FT-IR spectroscopy combined with pyridine adsorption.

\begin{tabular}{|c|c|c|c|c|c|c|}
\hline \multirow[b]{2}{*}{ Sample } & \multicolumn{3}{|c|}{ Brønsted Acidity ( $\mu \mathrm{mol} \mathrm{Py} \mathrm{g}^{-1}$ ) } & \multicolumn{3}{|l|}{ Lewis Acidity $\left(\mu \mathrm{mol} \mathrm{Py} \mathrm{g}^{-1}\right)$} \\
\hline & $\mathrm{T}=150^{\circ} \mathrm{C}$ & $\mathrm{T}=250^{\circ} \mathrm{C}$ & $\mathrm{T}=350^{\circ} \mathrm{C}$ & $\mathrm{T}=150^{\circ} \mathrm{C}$ & $\mathrm{T}=250^{\circ} \mathrm{C}$ & $\mathrm{T}=350^{\circ} \mathrm{C}$ \\
\hline SA2 $5^{\mathrm{a}}$ & 191 & 133 & 84 & 129 & 101 & 75 \\
\hline BEA & 207 & 158 & 128 & 102 & 87 & 83 \\
\hline $\mathrm{Re} / \mathrm{BEA}$ & 182 & 153 & 79 & 89 & 81 & 71 \\
\hline 60BEA:40MFI* & 217 & 166 & 130 & 92 & 79 & 78 \\
\hline $\mathrm{Re} /\left(60 \mathrm{BEA}: 40 \mathrm{MFI}^{*}\right)$ & 200 & 156 & 119 & 77 & 70 & 52 \\
\hline 40BEA:60MFI* & 144 & 113 & 96 & 53 & 45 & 44 \\
\hline $\mathrm{Re} /\left(40 \mathrm{BEA}: 60 \mathrm{MFI}^{*}\right)$ & 131 & 113 & 64 & 54 & 48 & 44 \\
\hline MFI* & 97 & 82 & 63 & 31 & 27 & 25 \\
\hline $\mathrm{Re} / \mathrm{MFI}^{*}$ & 92 & 79 & 54 & 26 & 25 & 25 \\
\hline $60 \operatorname{Re} / \mathrm{BEA}+40 \mathrm{Re} / \mathrm{MFI}^{* \mathrm{~b}}$ & 146 & 123 & 73 & 84 & 59 & 53 \\
\hline $40 \operatorname{Re} / \mathrm{BEA}+60 \operatorname{Re} / \mathrm{MFI}^{* \mathrm{~b}}$ & 128 & 109 & 64 & 51 & 47 & 38 \\
\hline
\end{tabular}

\footnotetext{
a Acidity normalized to the zeolite content of the SA25 catalyst.

b Values calculated from the pure Re-zeolites according to their proportion in the mixture.
} 

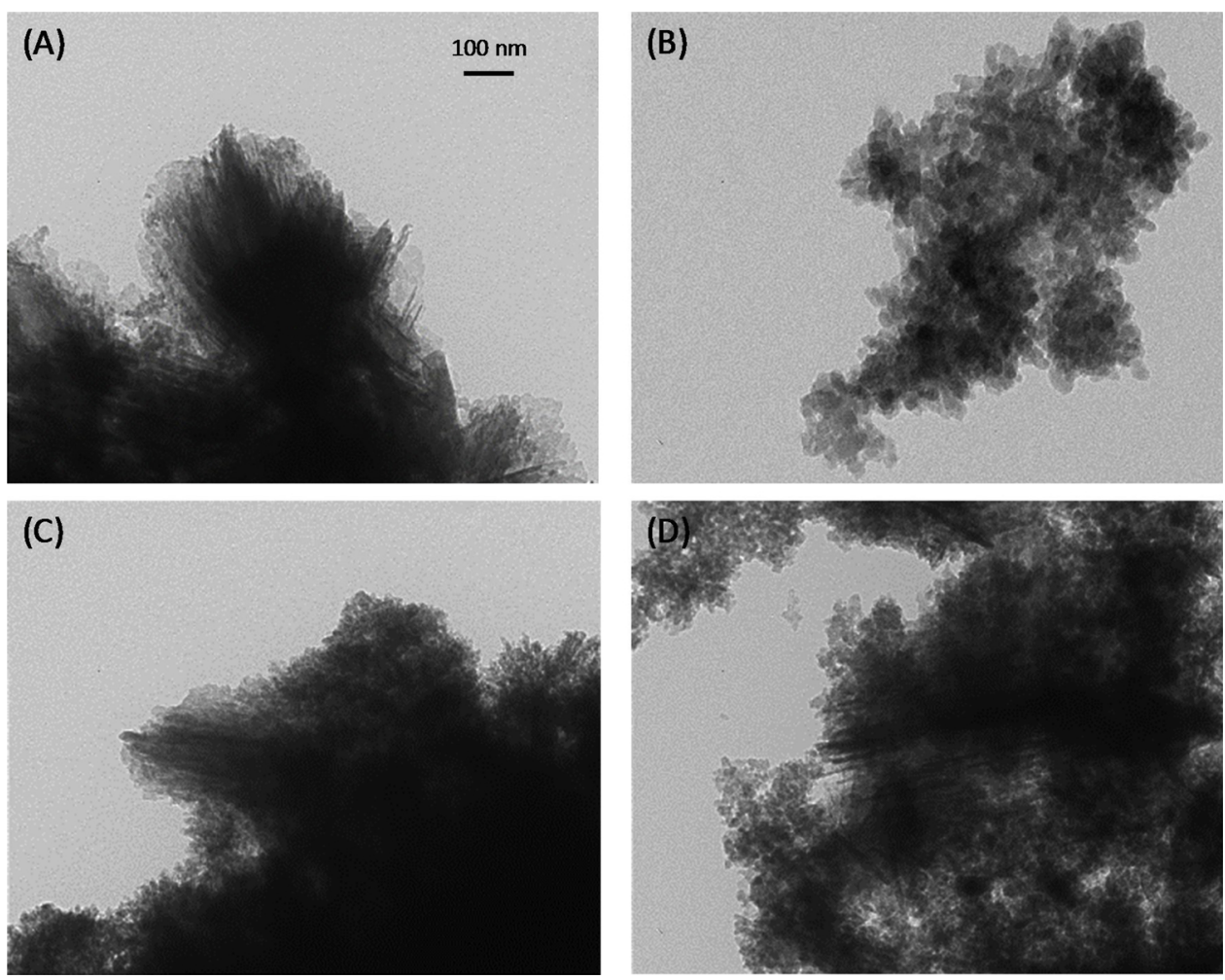

Fig. 3. TEM images of (A) single MFI*, (B) single BEA, (C) 40BEA:60MFI* and (D) 60BEA:40MFI* samples.

amount of BAS that would correspond taking into account the acidity of the single Re-zeolites and their proportion in the mixture. Acidity of the benchmark catalyst SA25 has also been determined, and the $\mu \mathrm{mol}$ of pyridine have been normalized to the amount of zeolite in the composite. Total Brønsted acidity is in the range of that of catalyst $\mathrm{Re} /$ (60BEA:40MFI*), based on the 60BEA:40MFI* mixture obtained by cocrystallization.

\subsection{Catalytic tests}

\subsubsection{Catalytic conversion of a model feed}

A preliminary catalytic evaluation of the BEA:MFI* composites described in the previous section for the simultaneous dealkylation/ transalkylation of $\mathrm{C}_{9}$ alkylaromatics has been performed in a highthroughput reaction system (spider reactor), for the conversion of a model feedstock (70:30 wt/wt mixture of EMB and TMB). After activating the catalysts under $\mathrm{H}_{2}$ flow at $450{ }^{\circ} \mathrm{C}$ for 1 hour, the dealkylation/transalkylation reaction is performed at three different temperatures, 350, 375 and $400{ }^{\circ} \mathrm{C}$, in three consecutive steps and keeping the catalyst on stream for $16 \mathrm{~h}$ at each of these temperatures. In a final step, the catalysts are tested again at $350{ }^{\circ} \mathrm{C}$ in order to determine their stability towards deactivation.

Fig. 6 shows the EMB, TMB and overall (EMB + TMB) conversion vs. time on stream (TOS) obtained for the benchmark catalyst SA25, for the two catalysts based on the one-pot synthesis beta-pentasil aggregates (60BEA:40MFI* and 40BEA:60MFI*), and for the catalyst prepared by physical mixture of the Re loaded BEA and MFI* zeolites (synthesized following the same procedure) in a 60:40 wt/wt proportion.

As can be seen in Fig. 6, the catalysts based on the zeolites synthesized in this work do not deactivate with TOS, independently of the procedure used for their preparation (one-pot co-crystallization of the BEA and MFI* zeolites or physical mixture of the synthesized BEA and MFI* samples). Indeed, the activity of these catalysts obtained during the first and last step of the experiment, both performed at $350^{\circ} \mathrm{C}$, is the same. However, the benchmark reference, SA25, does deactivate significantly with TOS, as evidenced by the lower conversion obtained during the last step at $350^{\circ} \mathrm{C}$, when compared to the conversion obtained with the fresh catalyst. Taking into account that the BAS density of the reference catalyst is in the same range as that of the $\mathrm{Re} /$ 60BEA:40MFI* sample, the longer catalyst life of the latter will be related to the intimate mixture of the individual crystals of BEA and MFI* in the aggregates obtained by co-crystallization, responsible for a higher selectivity, and to their small crystallite sizes. The two catalysts containing BEA and MFI* in a proportion of $60: 40, \mathrm{Re} / 60 \mathrm{BEA}: 40 \mathrm{MFI}^{*}$ and $60 \mathrm{Re} / \mathrm{BEA}+40 \mathrm{Re} / \mathrm{MFI}^{*}$, present comparable overall conversion. However, the latter, based on the physical mixture of the Re-loaded single zeolites, converts slightly more EMB, whereas the catalyst based on the co-crystallized BEA/MFI* mixture seems to be slightly more active for conversion of TMB.

Regarding the yield to xylenes and heavy alkylaromatics (Fig. 7), the two catalysts containing a higher beta content (Re/60BEA:40MFI*, based on the bi-zeolite aggregate and the physical mixture 60Re/ $\mathrm{BEA}+40 \mathrm{Re} / \mathrm{MFI}^{*}$ ) yield more xylenes than the catalyst based on the one-pot synthesis aggregates with larger proportion of the medium pore catalyst (Re/40BEA:60MFI*). Moreover, the catalyst based on the BEA:MFI* mixture obtained by one-pot synthesis produces slightly more xylenes than the one based on the physical mixture of the single BEA and MFI* components. Thus, the one pot synthesis producing the co-crystallized BEA and MFI* nanocrystallites results in a more efficient catalyst for the conversion of EMB and TMB mixtures to xylenes, as compared to a catalyst prepared by the physical mixture of the two single zeolites in the same proportions. The TEM images enclosed in Fig. 3 showed that in the beta-pentasil aggregates obtained by direct synthesis, the mixture occurs at the nanometer scale, with close proximity and homogeneous distribution of the individual crystallites of the two different structures within the aggregates. This close proximity of the BEA and MFI* nanocrystals will enable a faster access of the toluene, formed by dealkylation of methylethylbenzene in the medium pore zeolite, to the large pore beta, where it will react more easily with 

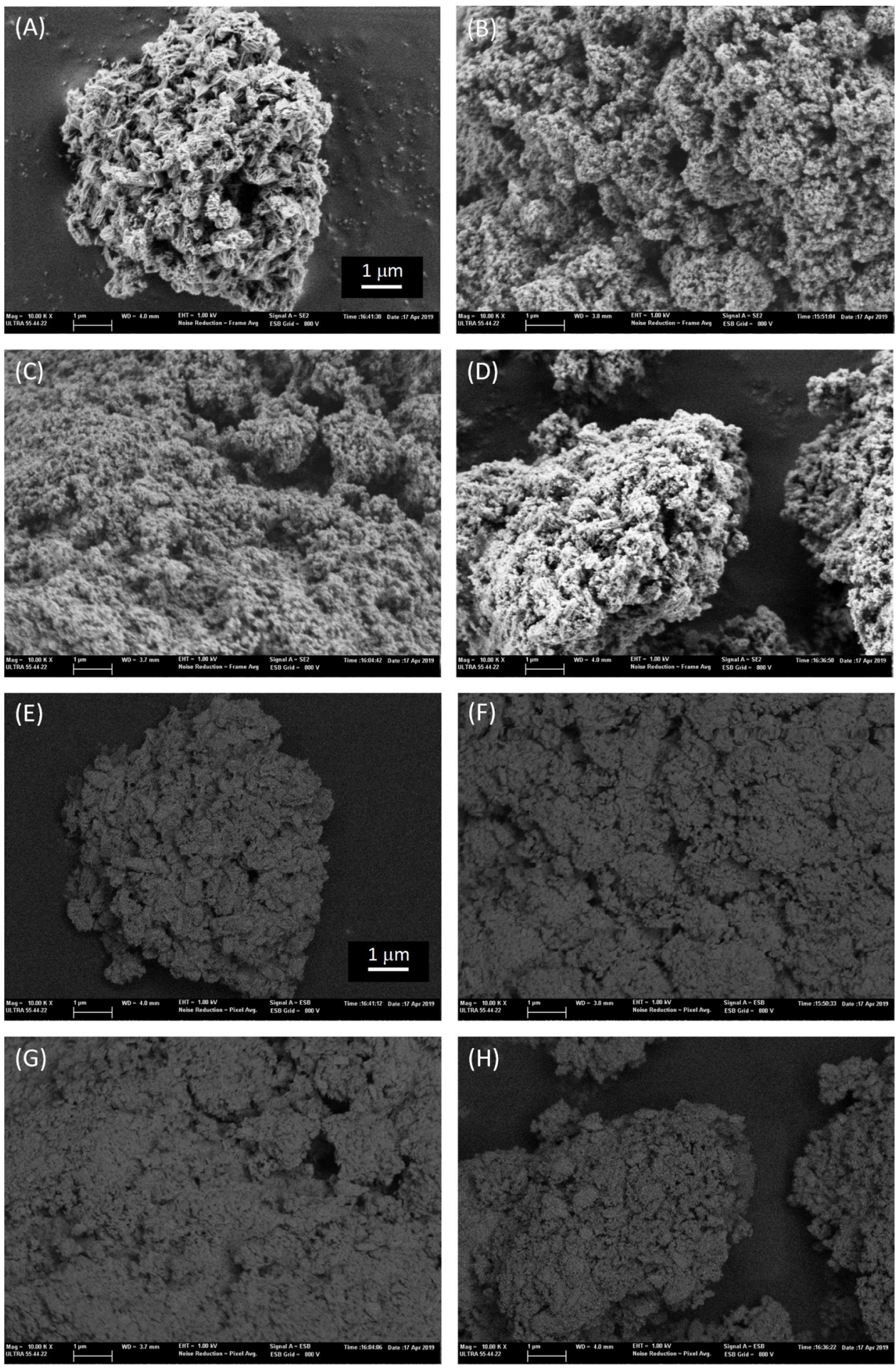

Fig. 4. FESEM images of (A) MFI*, (B) single BEA, (C) 40BEA:60MFI* and (D) 60BEA:40MFI* samples measured in the SE2 detector; (E) single MFI*, (F) single BEA, (G) 40BEA:60MFI* and (H) 60BEA:40MFI* samples measured in the BSE detector.

the trimethylbenzenes by transalkylation to produce xylenes. The reference catalyst, SA25, although being more selective to xylenes during the first stage of the experiment, at $350^{\circ} \mathrm{C}$ and short reaction times, is not able to maintain this high xylene yield due to its progressive deactivation with time on stream (see Fig. 7). The xylene's isomer distribution obtained in all cases was the one corresponding to the equilibrium at the reaction temperature. This lack of $p$-selectivity is what could be expected as the transalkylation reaction will occur, mainly, in the large pore beta component of the catalyst.
It has to be noted that alkylaromatics, such as those present in a heavy reformate (EMB, TMB), may undergo undesired reactions in the presence of an acid catalyst, leading to the formation of aromatics with 10 or more carbon atoms $\left(\mathrm{AC}_{10+}\right)$. If these bulkier compounds cannot diffuse out of the zeolite crystals through the pores of the crystalline structure because of steric limitations, they may block part of the channel systems or lead to heavier coke precursors. The small crystal sizes and, therefore, the short diffusion pathways of the zeolites synthesized by the procedure described in this work, favor the diffusion out 

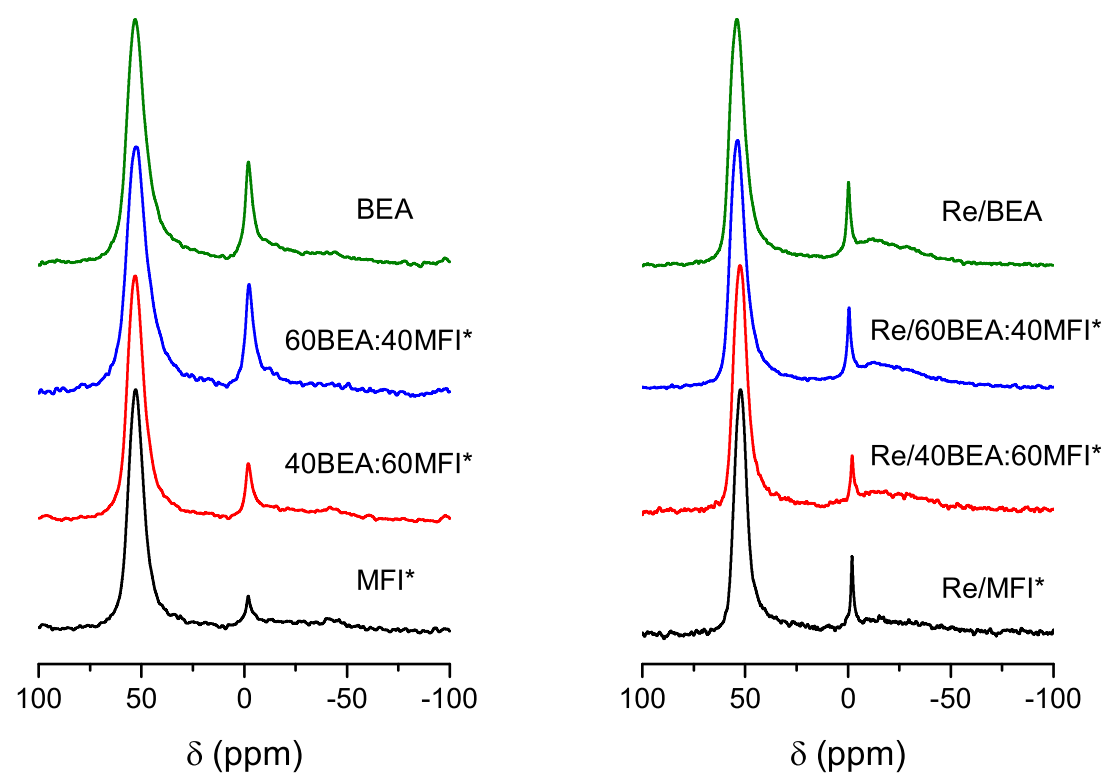

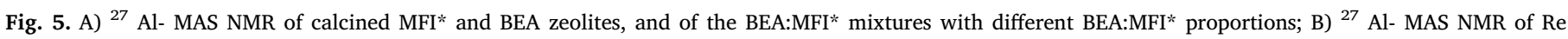
impregnated $\mathrm{MFI}^{*}\left(\mathrm{Re} / \mathrm{MFI}^{*}\right)$, BEA (Re/BEA), and BEA:MFI* mixtures with different BEA:MFI* proportions.

of the crystals, not only of the primary products, but also of part of the heavier $\mathrm{AC}_{10}+$ alkylaromatics formed by transalkylation of $\mathrm{TMB}$, avoiding their conversion into bulkier coke precursors inside the zeolite micropores and reducing, in this way, the deactivation rate of the catalyst with TOS.

Finally, Fig. 8 shows that the production of light ends, toluene and

\section{EMB conversion (\%)}

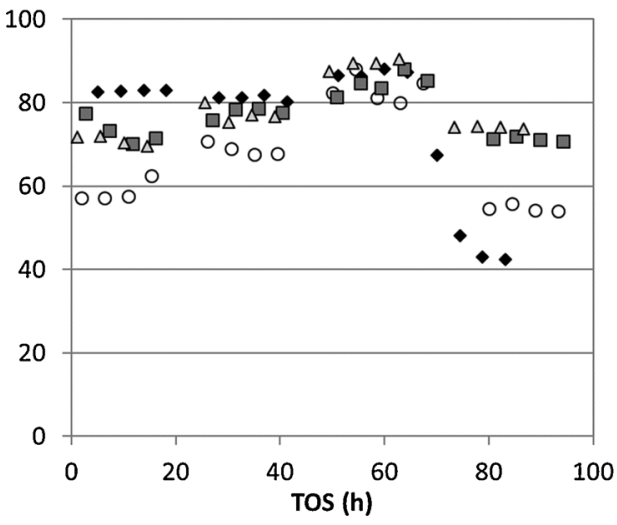

Overall conversion (\%)

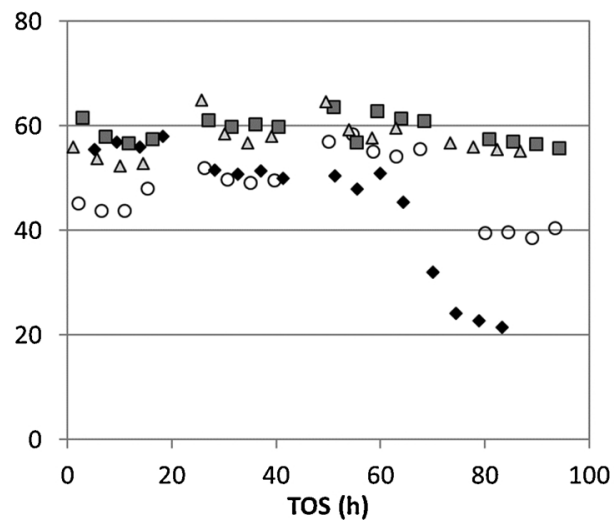

ethylbenzene with the one-pot synthesis mixtures is comparable to that of the benchmark catalysts.

The results presented so far show that the specific properties of the catalyst formed by aggregates obtained by one-pot synthesis, which involve small crystal size and intimate proximity of the MFI* and BEA nanocrystals at the nanometer scale, results in higher xylenes yield and

TMB conversion (\%)

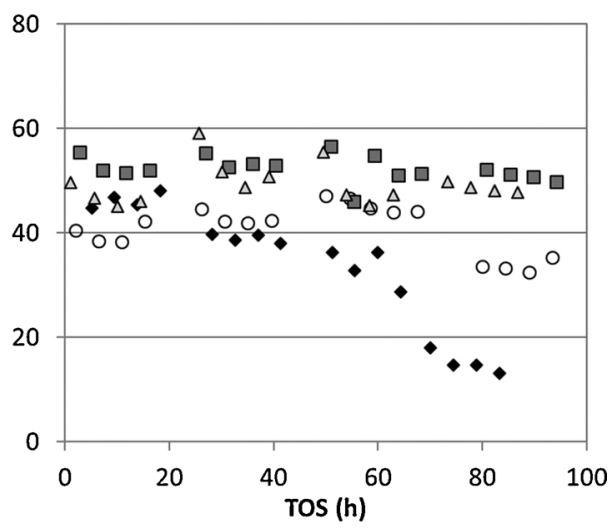

- SA25

O $\mathrm{Re} / 40 \mathrm{BEA}: 60 \mathrm{MFI}{ }^{*}$

$\square \operatorname{Re} / 60 \mathrm{BEA}: 40 \mathrm{MFI}{ }^{*}$

$\triangle 60 \mathrm{Re} / \mathrm{BEA}+40 \mathrm{Re} / \mathrm{MFI}^{*}$

Fig. 6. EMB, TMB and overall conversion obtained for the reference catalysts SA25 and for the catalysts based on the zeolites synthesized in this work. $\mathrm{T}=350-400^{\circ} \mathrm{C}, \mathrm{P}=20$ bar, WHSV $=10 \mathrm{~h}^{-1}, \mathrm{H}_{2} / \mathrm{HC}=8.5$ (molar). 
Xylenes yield (wt.\%)

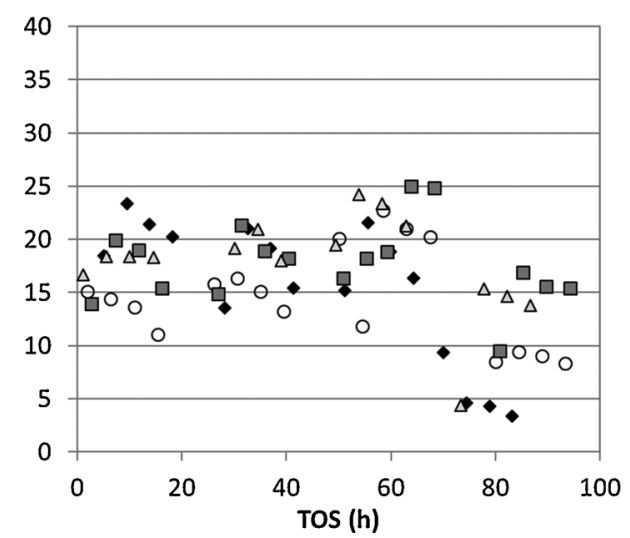

AC10+ yield (wt.\%)

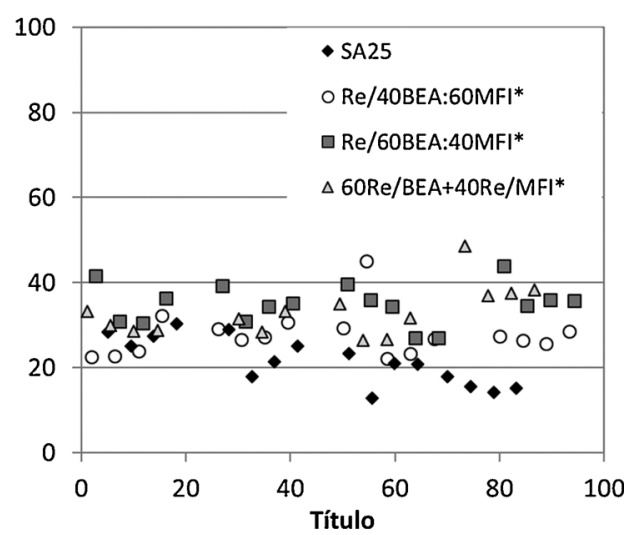

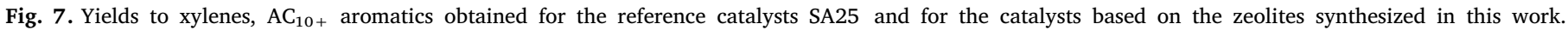
$\mathrm{T}=350-400^{\circ} \mathrm{C}, \mathrm{P}=20$ bar, WHSV $=10 \mathrm{~h}^{-1}, \mathrm{H}_{2} / \mathrm{HC}=8.5$ (molar).

reduced formation of coke precursors with the corresponding improvement in catalyst life. Regarding the reference SA25, although initially active and selective to xylenes, its yield to these aromatics decreases significantly with time on stream due to catalyst deactivation.

\subsubsection{Catalytic conversion of an industrial heavy reformate}

The results obtained with the model feed have evidenced the lower deactivation rate of the catalysts based on the one-pot synthesis BEA:MFI* aggregates presented in this work as compared to a reference benchmark catalyst. Moreover, their overall conversion and xylenes yield are higher than those obtained with the physical mixture of the

Light HC yield (wt.\%)

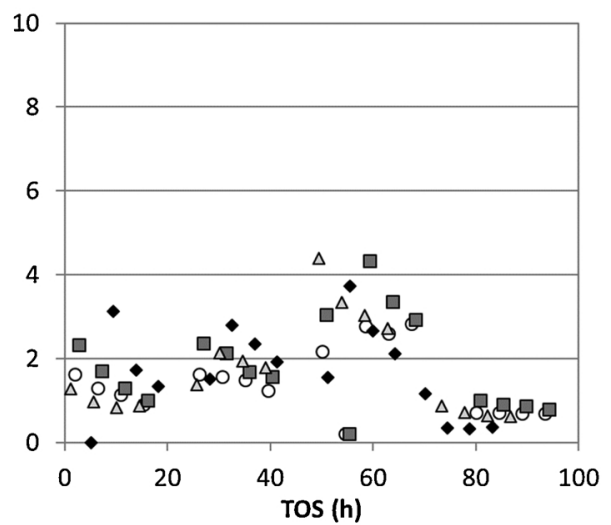

Ethylbenzene yield (wt.\%)

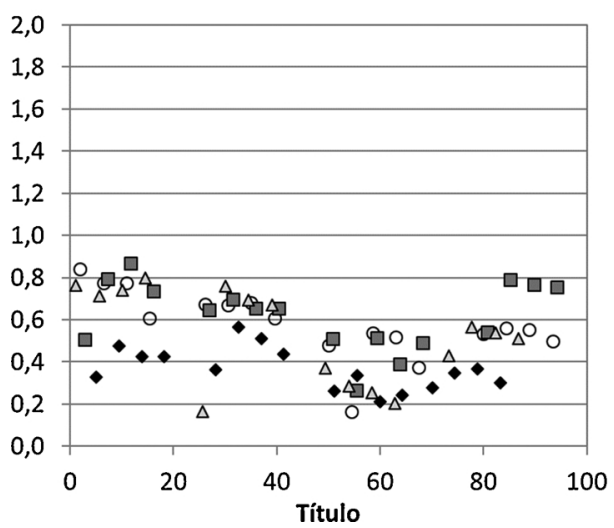

Re-loaded single beta and pentasil nanozeolites, with comparable crystal sizes and morphologies as the zeolites present in the aggregates obtained by co-crystallization (see Fig. 3). This improved catalytic behavior of the 60BEA:40MFI* mixture obtained by one-pot synthesis can be ascribed, as was said before, to the intimate proximity of the crystals of the two zeolite structures, which enhance the consecutive reactions of dealkylation/transalkylation on the medium pore MFI* and on the large pore BEA, respectively. However, it is important to confirm the good performance of these one-pot synthesis zeolite mixtures under conditions closer to those applied in industrial processes. Thus, the catalysts have been studied for the conversion of an industrial heavy

Toluene yield (wt.\%)

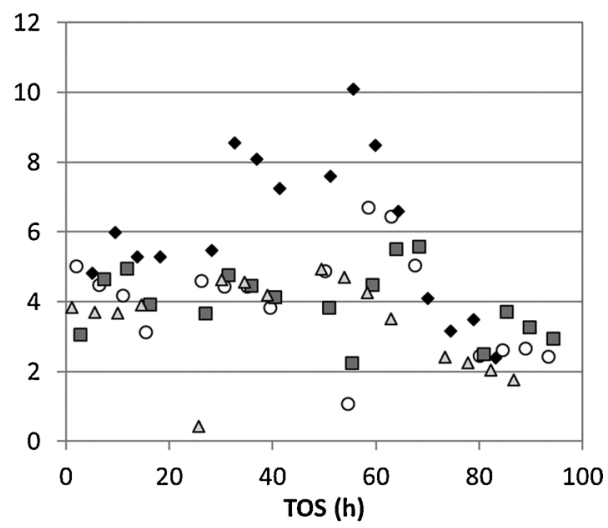

- SA25

O $\mathrm{Re} / 40 \mathrm{BEA}: 60 \mathrm{MFI} *$

$\square \operatorname{Re} / 60 \mathrm{BEA}: 40 \mathrm{MFI} *$

$\triangle 60 \mathrm{Re} / \mathrm{BEA}+40 \mathrm{Re} / \mathrm{MFI}^{*}$

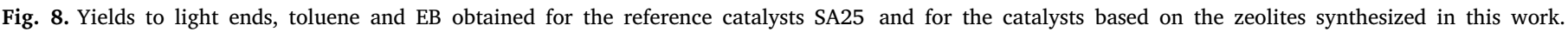
$\mathrm{T}=350-400^{\circ} \mathrm{C}, \mathrm{P}=20 \mathrm{bar}$, WHSV $=10 \mathrm{~h}^{-1}, \mathrm{H}_{2} / \mathrm{HC}=8.5$ (molar). 
TMB conversion (\%)

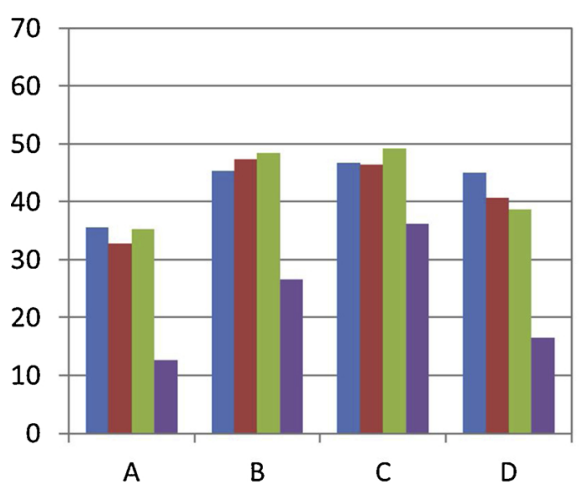

Overall conversion (\%)

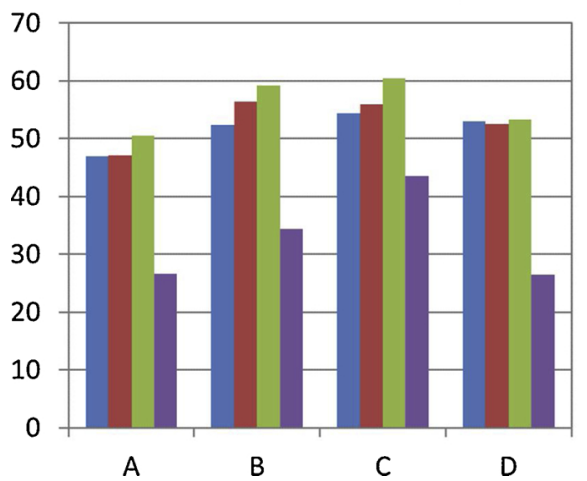

EMB conversion (\%)

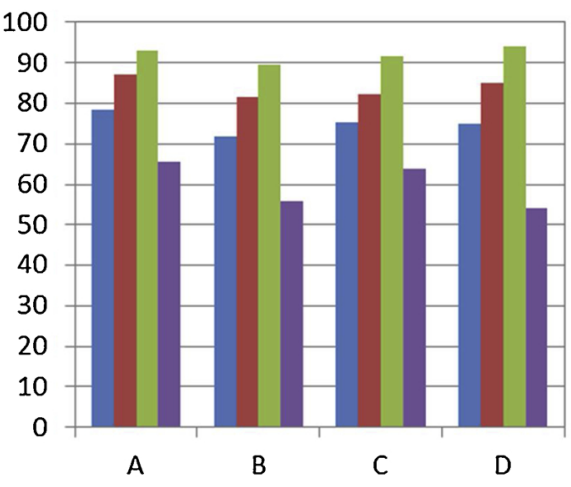

$\square 350^{\circ} \mathrm{C}=375^{\circ} \mathrm{C}=400^{\circ} \mathrm{C}=350^{\circ} \mathrm{C} \_2$
A. SA25
B. $60 \mathrm{Re} / \mathrm{BEA}+40 \mathrm{Re} / \mathrm{MFI} *$
C. $\mathrm{Re} / 60 \mathrm{BEA}: 40 \mathrm{MFI} *$
D. $\mathrm{Re} / 40 \mathrm{BEA}: 60 \mathrm{MFI}^{*}$

Fig. 9. Conversion of an industrial heavy reformate feed obtained with the reference catalysts SA25 and the catalysts based on the zeolites synthesized in this work. $\mathrm{T}=350-400^{\circ} \mathrm{C}, \mathrm{P}=20 \mathrm{bar}, \mathrm{WHSV}=10 \mathrm{~h}^{-1}, \mathrm{H}_{2}: \mathrm{HC}=4: 1\left(\mathrm{~mol} \mathrm{~mol}^{-1}\right)$.

reformate stream, whose composition is given in Table 1 , and under more severe reaction conditions $\left(\mathrm{H}_{2}: \mathrm{HC}=4: 1 \mathrm{~mol} \mathrm{~mol}^{-1}\right.$, $\mathrm{T}=350-400^{\circ} \mathrm{C}, \mathrm{P}=20 \mathrm{bar}$ and WHSV $=10 \mathrm{~h}^{-1}$ ).

Fig. 9 shows the EMB (dealkylation), TMB (transalkylation) and overall $(\mathrm{EMB}+\mathrm{TMB})$ conversion for the two zeolite mixtures obtained by one-pot synthesis, for the physical mixture of the BEA and MFI* zeolites obtained by means of the same synthesis procedure and for the reference SA25. As in the case of the model feed conversion, the catalysts have been tested at four consecutive temperatures of 350, 375 and $400{ }^{\circ} \mathrm{C}$, and a final experiment is performed at $350^{\circ} \mathrm{C}$ in order to estimate the deactivation degree. Under these more severe conditions (lower $\mathrm{H}_{2} / \mathrm{HC}$ ratios), the initial conversion of the fresh catalysts is not recovered in any case, indicating a partial deactivation of all the catalysts along the consecutive steps of the run, and the largest activity loss occurs with the reference SA25. The smallest conversion decrease when comparing the overall conversion level obtained during the first and the final experiment, both at $350{ }^{\circ} \mathrm{C}$, corresponds to sample $\mathrm{Re} /$ 60EA:40MFI*, based on the one-pot synthesized aggregate with larger beta content. In fact, deactivation for this catalyst is lower than for the catalyst obtained by physical mixture, 60Re/BEA + 40Re/MFI*. Thus, also when converting an industrial heavy reformate feed under industrially relevant conditions, the proximity of the BEA and MFI* nanocrystals in the aggregates improves the stability towards deactivation. In fact, the mixture of the individual BEA and MFI* crystals will improve the efficiency of the overall process by reducing the distance between the sites where toluene is formed by dealkylation on the medium pore zeolite and the sites where it has to react with TMB to form xylenes by transalkylation on the large pore beta. This will increase the selectivity to the desired products and will reduce the formation of coke precursors.

Fig. 9 shows that, when comparing the different catalysts, the differences in overall conversion are mainly due to the differences in their
TMB conversion, which is directly related to their transalkylation capacity. So, the reference SA25 is slightly more active for dealkylation but significantly less effective for conversion of TMB, presenting, therefore, a lower overall conversion as compared to the catalysts based on the co-crystallized nanozeolites. As mentioned in the previous section, the BAS density of the reference catalyst is in the same range as that of the Re/60BEA:40MFI* sample. Thus, the longer catalyst life of the catalyst based on the mixture obtained by co-crystallization will result from the intimate mixture of the individual BEA and MFI* nanocrystals in the aggregates and from their small crystallite sizes. Comparing the catalysts based on the one-pot synthesized BEA:MFI* aggregates, the catalyst containing lower proportion of beta and more of the medium pore component (Re/40BEA:60MFI*) converts more $\mathrm{EMB}$, as could be expected due to its higher content of MFI*, but its overall conversion is lower due to a lower TMB conversion. Regarding the two catalysts with $60 \mathrm{wt} \%$ BEA and $40 \mathrm{wt} \% \mathrm{MFI}^{*}$, although the differences are not large, the one obtained by co-crystallization ( $\mathrm{Re}$ / 60BEA:40MFI*) presents higher overall conversion at the lowest temperatures than the physical mixture of the pure Re/BEA plus pure Re/ $\mathrm{MFI}^{*}$ combined in the same proportion (60-40 wt\%), evidencing a higher activity. This could be explained by the fact that the former has a higher total Brønsted acid site density than the one calculated from the single Re-zeolites in 60:40 proportion (see Table 4).

Thus, the close proximity of the BEA and MFI* mixtures prepared by one-pot synthesis has a clear benefit from the activity and catalyst life point of view, also when processing an industrial heavy reformate.

Regarding the product distribution, the xylenes production is slightly larger over sample Re/60BEA:40MFI* than over 60Re/ BEA + 40Re/MFI*, prepared by physical mixture (see Fig. 10), and the former produces less amount of light hydrocarbons (see Fig. 11). Reference catalyst SA25 yields the highest amounts of light hydrocarbons and toluene (see Fig. 11), in good agreement with its higher EMB 

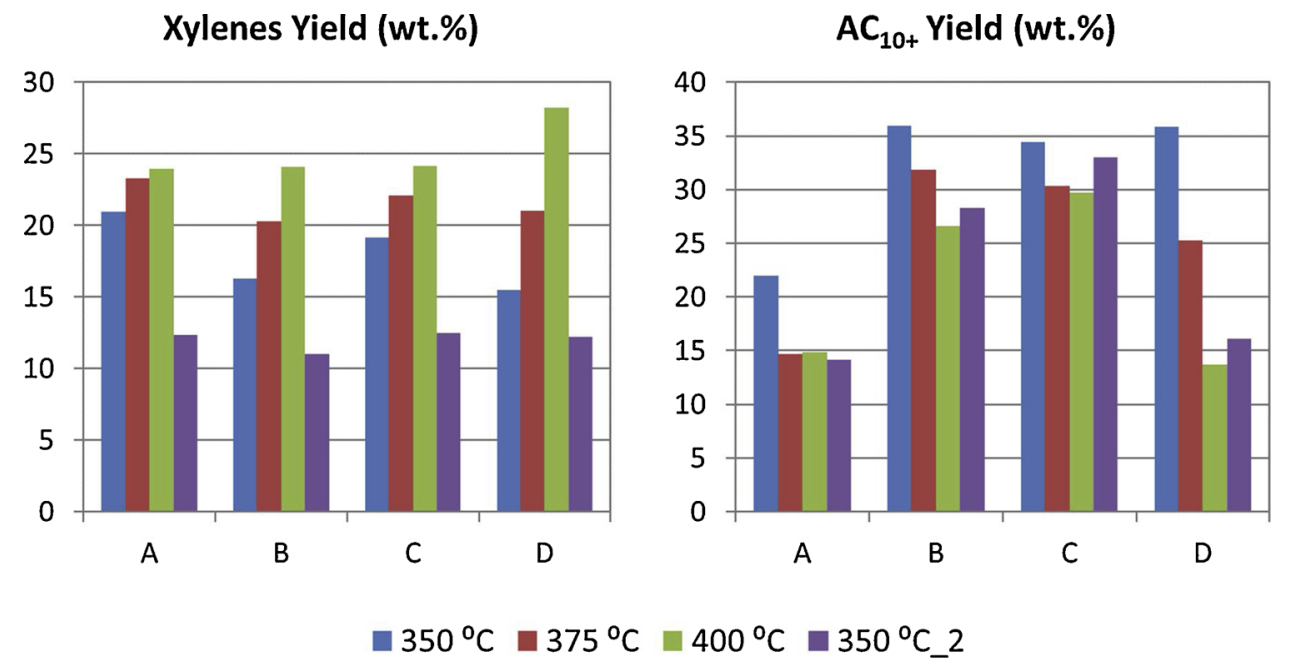
A. SA25
B. $60 \mathrm{Re} / \mathrm{BEA}+40 \mathrm{Re} / \mathrm{MFI}{ }^{*}$
C. $\mathrm{Re} / 60 \mathrm{BEA}: 40 \mathrm{MFI}^{*}$
D. $\mathrm{Re} / 40 B E A: 60 \mathrm{MFI}^{*}$

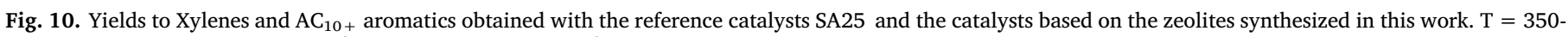
$400^{\circ} \mathrm{C}, \mathrm{P}=20 \mathrm{bar}, \mathrm{WHSV}=10 \mathrm{~h}^{-1}, \mathrm{H}_{2}: \mathrm{HC}=4: 1\left(\mathrm{~mol} \mathrm{~mol}^{-1}\right)$.

\section{conversion capacity.}

Finally, the different proportion of the zeolitic components present in the aggregates obtained by co-crystallization also influences the product distribution, and the sample with higher MFI* component, Re/ 40BEA:60MFI*, produces larger amount of light HC and toluene than the sample with higher BEA component, Re/60BEA:40MFI*, in good agreement with its higher EMB conversion. Catalyst Re/40BEA:60MFI*, richer in the medium pore MFI* produces also more xylenes at the highest reaction temperature, $400{ }^{\circ} \mathrm{C}$, and significantly less heavy alkylaromatics, $\mathrm{AC}_{10+}$. Its higher content of $\mathrm{MFI}^{*}$, with pores too narrow

\section{Light HC Yield (wt.\%)}

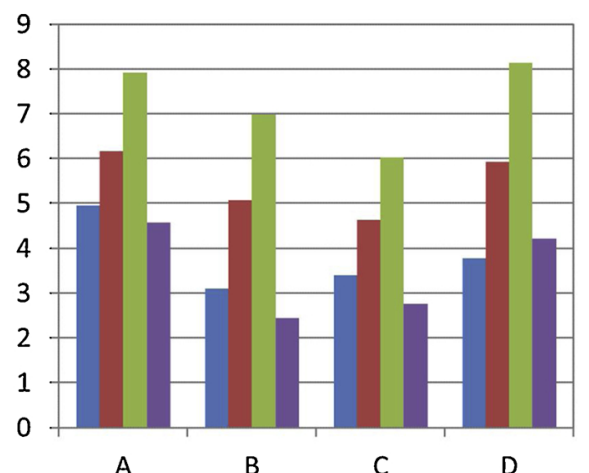

Ethylbenzene Yield (wt.\%)

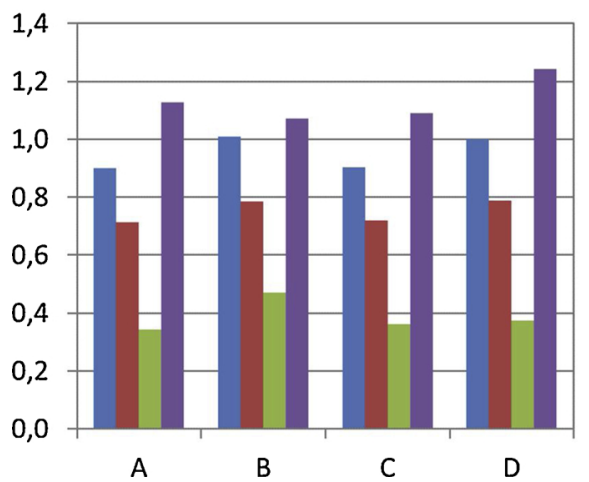

Toluene Yield (wt.\%)

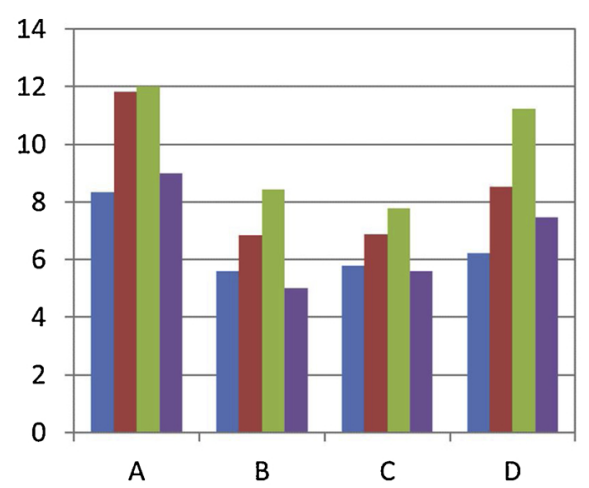

$\square 350^{\circ} \mathrm{C}-375^{\circ} \mathrm{C}-400^{\circ} \mathrm{C}-350^{\circ} \mathrm{C} \_2$
A. SA25
B. 60Re/BEA+40Re/MFI*
C. Re/60BEA:40MFI*
D. Re/40BEA:60MFI*

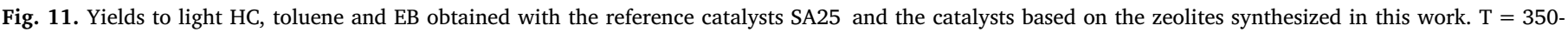
$400^{\circ} \mathrm{C}, \mathrm{P}=20 \mathrm{bar}, \mathrm{WHSV}=10 \mathrm{~h}^{-1}, \mathrm{H} 2: \mathrm{HC}=4: 1\left(\mathrm{~mol} \mathrm{~mol}^{-1}\right)$. 
for transalkylation to occur, could favor dealkylation of the heavier $\mathrm{AC}_{10+}$ as described for disproportionation of ethylbenzene [35,36].

The results presented in this section, corresponding to the direct conversion of an industrial heavy reformate, are in good agreement with those obtained for the conversion of the model feed, and evidence the benefits of the catalysts based on one-pot synthesis of BEA:MFI* aggregates from the point of view of activity, xylenes yield and catalyst life. Moreover, the procedure described in this work for preparing heavy reformate conversion catalysts presents an additional advantage as compared to those previously described: it allows obtaining the two zeolite structures intimately mixed together in the same catalyst by means of a single synthesis step.

\section{Conclusions}

Nanocrystalline beta:pentasil aggregates have been prepared by a single step synthesis procedure, which enables controlling the proportion of the two different zeolites structures in the final material by means of the composition of the synthesis gel. The small crystal sizes of the BEA and MFI* zeolites obtained by co-crystallization lead to high external surfaces $\left(\geq 167 \mathrm{~m}^{2} \mathrm{~g}^{-1}\right)$ and mesopore volumes ( $\geq 0.34 \mathrm{~cm}^{3} \mathrm{~g}^{-1}$ ) while preserving the microporous structure. Thus, the samples present high accessibility and reduced diffusion path lengths.

The catalysts based on these one-pot synthesis BEA:MFI* mixtures present higher activity and improved catalyst life, not only when compared with a reference benchmark catalyst, but also when compared with a catalyst based on the physical mixtures -in the same proportion- of BEA and MFI* nanozeolites obtained following the same procedure, and comparable in crystal size and morphology. This improved catalytic behavior of the co-crystallized BEA:MFI* aggregates can be ascribed, not only to their small crystallite size, but also to the intimate proximity of the crystals of the two zeolite structures, in the nanometer scale, that will enhance the consecutive reaction steps of dealkylation and transalkylation on the medium and large pore zeolite, respectively.

Thus, the bifunctional catalysts based on these zeolite aggregates obtained by co-crystallization are able to couple, in an effective way, the dealkylation of EMB to toluene and its transalkylation with the $\mathrm{TMB}$, also present in the feed. Moreover, the procedure described presents the advantage of obtaining both zeolites in a single synthesis step and with an easily tunable composition.

\section{Acknowledgements}

This work has been supported by Saudi Aramco, by the Spanish Government-MICINN through "Severo Ochoa" (SEV 2012-0267) and RTI2018-101033-B-I00, by the European Union through ERC-AdG2014-671093 (SynCatMatch) and by the Fundación Ramón Areces through a research contract of the "Life and Materials Science" program. We thank Belén Esparcia for technical assistance, and the Electron Microscopy Service of the UPV for their help in sample characterization.

\section{References}

[1] S.A. Ali, M.A. Ali, K. Al-Nawad, C. Ercan, Y. Wang, Parametric study of dealkylation-transalkylation reactions over mordenite-based bi-functional catalysts, Appl. Catal. A 393 (2011) 96-108.

[2] T. Kim, G.-P. Kim, J. Jang, S.E. Shim, W.-S. Ahn, S.-H. Baeck, An investigation on the selective hydrodealkylation of C9 + aromatics over alkali-treated Pt/H-ZSM-5 zeolites, Catal. Sci. Technol. 6 (2016) 5599-5607.

[3] T. Onodera, T. Sakai, Y. Yamasaki, K. Sumitani, M. Sueoka, Selective Dealkylation of Alkyl-Substituted Aromatic Hydrocarbons, EP27157A1, (1981) to Teijin Petrochemical Industries, Ltd., Japan.

[4] S.A. Tabak, R.A. Morrison, Benzene, Toluene and Xylene Manufacture, US4341622A, (1982) to Mobil Oil Corp., USA.

[5] T. Yamada, A. Aoki, Benzene and Methyl-Substituted Benzene Derivatives, EP165470A2, (1985) to Idemitsu Petrochemical Co., Ltd., Japan.

[6] A.-h. Wu, C.A. Drake, R.J. Melton, Hydrodealkylation Process and Catalysts for
Producing C6-8 Aromatic Hydrocarbons and C1-5 Alkanes from Alkyl-Substituted C9-12 Aromatic Hydrocarbons, US5689026A, (1997) to Phillips Petroleum Co., USA.

[7] J.M. Serra, E. Guillon, A. Corma, Optimizing the conversion of heavy reformate streams into xylenes with zeolite catalysts by using knowledge base highthroughput experimentation techniques, J. Catal. 232 (2005) 342-354.

[8] D.L. King, E.G. Derouane, J. De Deken, T. Masuda, S. Nishikawa, H. Fujii, M. Adachi, Selective Catalytic Conversion of a C9 Aromatic Feedstock Containing Substantial Amounts of Ethyl Substituted Aromatic Components to a Product Rich in Toluene and/or Xylenes, WO9812159A2, (1998) to Mitsubishi Oil Co., Ltd., Japan.

[9] M.L. Bricker, F.S. Modica, Zeolite-Supported Palladium and Germanium-Containing Transalkylation Catalysts for Alkylaromatic Hydrocarbons, US20080026930A1, (2008) to Uop LLC, USA.

[10] J.S. Buchanan, R.J. Cimini, R.A. Crane, W.F. Lai, J.G. Santiesteban, D.A. Stachelczyk, H.-k. Timken, W.A. Weber, D.L. Stern, Heavy Aromatics Processing, WO2004046278A1, (2004) to Exxonmobil Chemical Patents Inc., USA.

[11] J.M. Serra Alfaro, A. Corma, E. Guillon, Catalyst Comprising a 10MR Zeolite and a 12MR Zeolite and its use in the Transalkylation of Alkylaromatic Hydrocarbons, EP1586376A1, (2005) to Institut Francais du Petrole, Fr.

[12] J.M. Serra, E. Guillon, A. Corma, A rational design of alkyl-aromatics dealkylationtransalkylation catalysts using C8 and C9 alkyl-aromatics as reactants, J. Catal. 227 (2004) 459-469.

[13] R. Ichioka, S. Yamakawa, H. Okino, Process for Producing Xylene, EP731071A1, (1996) to Toray Industries, Inc., Japan.

[14] C. Ercan, Y. Wang, Multimetal Zeolites Based Catalyst for Transalkylation of Heavy Reformate to Produce Xylenes and Petrochemical Feedstocks, US20130261364A1, (2013) to Saudi Arabian Oil Company, Saudi Arabia.

[15] Y. Wang, C. Ercan, Process for the Production of Xylenes and Light Olefins from Heavy Aromatics Through Transalkylation, US20130261365A1, (2013) to Saudi Arabian Oil Company, Saudi Arabia.

[16] W. Vermeiren, J.-P. Gilson, Impact of zeolites on the petroleum and petrochemical industry, Top. Catal. 52 (2009) 1131-1161.

[17] E.M. Gallego, M.T. Portilla, C. Paris, A. León-Escamilla, M. Boronat, M. Moliner, A. Corma, "Ab initio" synthesis of zeolites for preestablished catalytic reactions, Science 355 (2017) 1051-1054.

[18] S.H. Baeck, G.J. Kim, D.-K. Noh, T.Y. Jang, T.-Y. Kim, Y.S. Ahn, C.-J. Song, S. C. Paik, Method for Selective Dealkylation of Alkyl-Substituted C9+ Aromatic Compounds Using Bimodal Porous Dealkylation Catalyst at Low Temperature, US20130165727A1, (2013) to Inha-Industry Partnership Institute, S. Korea; S-Oil Corporation.

[19] K. Iwayama, T. Inoue, Conversion of Xylenes Containing Ethyl Benzene, EP42754A1, (1981) to Toray Industries, Inc., Japan.

[20] S.H. Oh, S.I. Lee, K.H. Seong, Y.S. Kim, J.H. Lee, J. Woltermann, W.E. Cormier, Y.F. Chu, Heavy aromatics upgrading using noble metal promoted zeolite catalyst, Stud. Surf. Sci. Catal. 142A (2002) 887-894.

[21] Taoray (UOP), https://www.uop.com/processing-solutions/petrochemicals/ benzene-para-xylene-production.

[22] TransPlus (ExxonMobil), https://www.exxonmobilchemical.com/en/products-andservices/technology-licensing-and-services/xylenes-production.

[23] TAC-9 (TORAY), https://www.toray.jp/chemical/en/inorganic/ino 006.html.

[24] E.P. Boldingh, M.G. Gatter, R.W. Broach, D.S. Lafyatis, UZM-14 for improved performance in aromatic transalkylation, 247th ACS National Meeting \& Exposition (2014) pp. IEC-25.

[25] C.P. Nicholas, E.P. Boldingh, M.R. Schreier, Aromatic Transalkylation Using UZM44 Aluminosilicate Zeolite Catalyst, US8609921B1, (2013) to UOP LLC, USA.

[26] S.A. Ali, A.M. Aitani, C. Ercan, Y. Wang, S. Al-Khattaf, Conversion of heavy reformate into xylenes over mordenite-based catalysts, Chem. Eng. Res. Des. 89 (2011) 2125-2135.

[27] S.A. Ali, A.M. Aitani, J. Čejka, S.S. Al-Khattaf, Selective production of xylenes from alkyl-aromatics and heavy reformates over dual-zeolite catalyst, Catal Today 243 (2015) 118-127.

[28] M. Choi, K. Na, J. Kim, Y. Sakamoto, O. Terasaki, R. Ryoo, Nature (London, UK 461 (2009).

[29] C.A. Emeis, Determination of integrated molar extinction coefficients for infrared absorption bands of pyridine adsorbed on solid acid catalysts, J. Catal. 141 (1993) 347-354.

[30] IZA Database of Zeolite Structures, The pentasil Family, (2019) http://europe.izastructure.org/IZA-SC/intergrowth families/Pentasils.pdf.

[31] G. Perego, M. Cesari, G. Allegra, Ordered and disordered structures in borosilicates with a pentasil-type framework, J. Appl. Cryst. 17 (1984) 403-410.

[32] G. Perego, G. Bellussi, A. Carati, R. Millini, V. Fattore, Disordered pentasil-type borosilicates, ACS Symp. Series 398 (1989) 360-373.

[33] E.M. Gallego, C. Paris, M.R. Díaz-Rey, M.E. Martínez-Armero, J. Martínez-Triguero, C. Martínez, M. Moliner, A. Corma, Simple organic structure directing agents for synthesizing nanocrystalline zeolites, Chem. Sci. 8 (2017) 8138-8149.

[34] A. Omegna, M. Vasic, J. Anton van Bokhoven, G. Pirngruber, R. Prins, Dealumination and realumination of microcrystalline zeolite beta: an XRD, FTIR and quantitative multinuclear (MQ) MAS NMR study, Phys. Chem. Chem. Phys. 6 (2004) 447-452.

[35] D.S. Santilli, The mechanism of aromatic transalkylation in ZSM-5, J. Catal. 99 (1986) 327-334.

[36] N. Arsenova, W.O. Haag, H.G. Karge, Kinetics study of ethylbenzene disproportionation with medium and large pore zeolites, Stud. Surf. Sci. Catal. 105 (1997) 1293-1300. 